\title{
CONTROLE DE LARVAS DE Diloboderus abderus COM INSETICIDAS EM TRIGO
}

\author{
CONTROL OF Diloboderus abderus LARVAE WITH INSECTICIDES \\ IN WHEAT
}

\author{
Mauro Tadeu Braga da Silva ${ }^{1}$ Adriano Boss ${ }^{2}$
}

\section{RESUMO}

A larva de Diloboderus abderus Sturm (Coleoptera: Melolonthidae) é uma praga importante da cultura do trigo (Triticum aestivum L.) em plantio direto na região Sul do Brasil. Este estudo teve como objetivo avaliar diferentes inseticidas aplicados nas sementes (fipronil e tiametoxam) e via pulverização do solo (clorpirifós e lambdacialotrina) para o controle dessa praga. A eficiência dos inseticidas foi determinada através do número de larvas vivas no solo aos 30,60 e 90 dias após a emergência das plantas (DAE), da massa seca da parte aérea das plantas aos 90 DAE e da produção de grãos. Foram observadas correlações negativas significativas entre a dose dos inseticidas fipronil e tiametoxam e o número de larvas, e correlações positivas significativas entre estes inseticidas e a massa seca da parte aérea e a produtividade de grãos. Infestações de larvas nas testemunhas não tratadas reduziram a produtividade em relação às áreas tratadas com inseticidas. A produtividade incrementou à medida que aumentou a eficiência de controle do inseto pelos inseticidas. Concluiu-se que clorpirifós (960 e $1200 \mathrm{~g}$ i.a./ha) $e$ lambdacialotrina a $25 \mathrm{~g}$ i.a./ha (formulação CE), aplicados em pulverização do solo, são eficientes para reduzir a população de larvas de D. abderus, garantindo a produtividade de grãos. Sugerem-se novos testes com os inseticidas fipronil, tiametoxam e lambdacialotrina (formulação SC) para determinar doses técnica e economicamente adequadas para o controle de larvas de $\boldsymbol{D}$. abderus em trigo.

Palavras-chave: insecta, coró, controle químico, tratamento de sementes, pulverização do solo, plantio direto.

\section{SUMMARY}

The larva of Diloboderus abderus Sturm (Coleoptera: Melolonthidae) is an important wheat (Triticum aestivum L.) pest under no-till system in the Southern region of Brazil. This study aimed to evaluate insecticides applied as seed treatment (fipronil and thiamethoxam) and in soil pulverization (chlorpyriphos and lambdacyhalothrin). The effectiveness of the insecticides were assessed by determining the number of larvae in the soil at 30, 60 and 90 days after emergence, the plant biomass at 90 days after emergence and the grain yield. Significant negative correlations were obtained between doses of fipronil and thiamethoxam with number of larvae. Significant positive correlations were observed between doses of fipronil and thiamethoxam with plant biomass and grain yield. Larvae infestations in non-treated plots caused significant yield losses when compared to plots treated with insecticides. Increasing control of larvae with insecticides increased the crop yield. It is concluded that chlorpyriphos (960 and $1200 \mathrm{~g}$ a.i./ha) and lambdacyhalothrin a $25 \mathrm{~g}$ i.a./ha (EC formulation), in soil pulverization, were efficient in reducing larval population and maintaining grain yields. Additional studies with thiamethoxam, fipronil and lambdacyhalothrin (CS formulation) are suggested to determine most efficient technical and economical dosages of these products to control D. abderus larvae in wheat.

Key words: insecta, white grubs, chemical control, seed treatment, soil pulverization, no-till.

\section{INTRODUÇÃO}

A larva de Diloboderus abderus Sturm 1826 (Coleoptera: Melolonthidae) é conhecida por coró-das-pastagens. É um inseto polífago, que ataca sementes, raízes, plântulas ou plantas em pastagens naturais ou artificiais, cultivos de lavoura, hortaliças e forrageiras (SILVA et al., 1968; MOREY \& ALZUGARAY, 1982; ALVARADO, 1983). A partir do final da década de 80, cresceu em importância como praga em áreas produtoras de cereais de inverno, no Sul do Brasil, e encontra ambiente favorável ao seu desenvolvimento em

\footnotetext{
${ }^{1}$ Engenheiro Agrônomo, Mestre, Pesquisador da FUNDACEP FECOTRIGO, CP 10, 98100-970, Cruz Alta, RS. E-mail:

fundacep@comnet.com.br. Autor para correspondência.

${ }^{2}$ Técnico Agrícola, Assistente de Pesquisa da FUNDACEP FECOTRIGO. 
solos com reduzida mobilização, como o sistema plantio direto (SILVA et al., 1994). $\mathrm{Na}$ cultura do trigo, em condições experimentais no sistema plantio direto, as perdas oscilaram entre 20 e $75 \%$, com infestações variando de 13 a 27 larvas $/ \mathrm{m}^{2}$, nas parcelas não tratadas (SILVA et al., 1995; SILVA, 2000). Vários métodos de controle, como o biológico (MOREY \& ALZUGARAY, 1982), o cultural (SILVA et al., 1995; SILVA et al., 1996) e o químico (ALVARADO $\boldsymbol{e t} \boldsymbol{a l}$., 1981; ALZUGARAY $\boldsymbol{e t}$ al., 1991; GASSEN, 1993; SILVA et al., 1995; SILVA, 2000) têm sido citados para combater esse inseto.

Considerando-se a dificuldade de se controlar as pragas de hábito subterrâneo no plantio direto com inseticidas, conduziu-se este estudo visando avaliar alguns inseticidas químicos, aplicados através do tratamento de sementes de trigo e da pulverização do solo no controle de larvas de $\boldsymbol{D}$. abderus.

\section{MATERIAL E MÉTODOS}

Dois experimentos foram conduzidos em diferentes anos e municípios do Estado do Rio Grande do Sul - RS localizados nas regiões geográficas do Planalto Médio (1999) e Missões (2000), em áreas manejadas no sistema plantio direto há mais de sete anos. Utilizaram-se as cultivares de trigo Fundacep 29 (semeadura em 05/06/1999) em Espumoso e Fundacep 37 (semeadura em 13/05/2000) em Maurício Cardoso. A semeadura foi feita com uma semeadora de treze linhas, espaçadas em $0,20 \mathrm{~m}$, na densidade de 330 sementes $/ \mathrm{m}^{2}$.

O delineamento experimental foi o de blocos aos acaso com seis repetições, sendo as parcelas experimentais constituídas de 40 fileiras de trigo por $8 \mathrm{~m}$ de comprimento. Os tratamentos avaliados (Tabelas 1 e 2) constaram de diferentes inseticidas aplicados nas sementes e no solo. Usaram-se $12 \mathrm{~kg}$ de sementes para cada dose de inseticida no tratamento de sementes, por ocasião da semeadura, misturados com auxílio de tambor rotativo de agitação mecânica durante cinco minutos. Os inseticidas usados em pulverização do solo foram aplicados com pulverizador costal com ar comprimido, equipado com bicos leque XR 11002 (1999) e bicos leque 11002 Magnus ADGA (2000), operando na pressão de 1 bar e volume de calda equivalente a 106 $\ell$ /há. Os experimentos foram conduzidos segundo as práticas recomendadas para a cultura do trigo no RS.

Avaliou-se o número de larvas antes da semeadura (pré-contagem) e aos 30,60 e 90 dias
Tabela 1 - Coeficientes e probabilidades de correlações linear (r), estimados por Pearson, entre doses de inseticidas e o número de larvas de Diloboderus abderus, sobreviventes em diferentes períodos após o tratamento, e a quantidade de massa seca da parte aérea e a produtividade de grãos de trigo. Cruz Alta, RS, 2001.

\begin{tabular}{|c|c|c|}
\hline \multirow{3}{*}{ Variáveis } & \multicolumn{2}{|c|}{ Coeficientes e probabilidades de correlações } \\
\hline & \multicolumn{2}{|c|}{ Inseticidas $^{1}$} \\
\hline & Fipronil (1999) & tiametoxam (2000) \\
\hline Dose x larva (Pré-contagem) ${ }^{2}$ & $\mathrm{r}=-0,11\left(0,5998^{\mathrm{ns}}\right)$ & $\mathrm{r}=-0,07\left(0,7495^{\mathrm{ns}}\right)$ \\
\hline Dose $x$ larva $(30)^{3}$ & $r=-0,65\left(0,0007^{*}\right)$ & $r=-0,49\left(0,0178^{*}\right)$ \\
\hline Dose x larva $(60)^{3}$ & $r=-0,78(0,0001 *)$ & $r=-0,68\left(0,0003^{*}\right)$ \\
\hline Dose $x$ larva $(90)^{3}$ & $r=-0,57(0,0048 *)$ & $r=-0,58\left(0,0040^{*}\right)$ \\
\hline Dose $x$ massa seca $(90)^{3}$ & $r=0,69(0,0002 *)$ & $r=0,93(0,0001 *)$ \\
\hline Dose $\mathrm{x}$ produtividade & $\mathrm{r}=0,73(0,0001 *)$ & $r=0,94(0,0001 *)$ \\
\hline
\end{tabular}

significância ao nível de $5 \%$ de probabilidade de erro; ${ }^{\text {ns }}$ : não significativo.

Standak 250 FS (250g i.a. de fipronil/litro); Cruiser 700 WS (700g i.a. de tiametoxam/quilo).

Antes da semeadura.

Dias após a emergência.

após a emergência das plantas (DAE), removendo-se uma camada de solo de $30 \mathrm{~cm}$ de profundidade, com dimensões de $25 \times 25 \mathrm{~cm}$, em quatro pontos por parcela em cada data de coleta. Determinou-se a massa seca da parte aérea das plantas aos 90 DAE. Para avaliação da produtividade de grãos, colheu-se a produção das 10 fileiras centrais de cada parcela, eliminando-se dois metros em cada extremidade, sendo corrigido para umidade $13 \%$.

Determinaram-se as correlações simples entre o fator eficiência dos inseticidas e as variáveis população de larvas (pré-contagem e 30, 60 e 90 DAE), massa seca da parte aérea e produtividade de grãos. Os dados de número de larvas foram submetidos ao cálculo da média e do intervalo de confiança (IC, significância em nível de 5\% de probabilidade de erro). Os dados de produtividade de grãos foram submetidos à análise de variância e, posteriormente, ao teste de Tukey com significância em nível de $5 \%$ de probabilidade de erro. Os dados de produtividade de grãos das doses dos inseticidas fipronil e tiametoxam foram representados pela melhor equação polinomial ajustada e pelo coeficiente de determinação $\left(r^{2}\right)$. Determinou-se também os pontos de máxima eficiência técnica (MET), obtida pela fórmula $X^{*}=-b_{1} / 2 b_{2}$ (COCHRAN \& COX, 1971), na qual os valores de $b_{1}$ e $b_{2}$ são dados pela equação polinomial ajustada.

\section{RESULTADOS E DISCUSSÃO}

As correlações entre as variáveis doses dos inseticidas fipronil e tiametoxam, aplicados nas sementes de trigo, e a população de larvas de $\boldsymbol{D}$. abderus (Tabela 1) e os intervalos de confiança 
Tabela 2 - Número $(\mathrm{N})$ de larvas $/ \mathrm{m}^{2}(\mathrm{X} \pm \mathrm{IC})$ e eficiência de inseticidas $(\% \mathrm{E})$ aplicados via tratamento de sementes e pulverização no solo para o controle de Diloboderus abderus na cultura do trigo. Cruz Alta, RS, 2001.

\begin{tabular}{|c|c|c|c|c|c|c|c|}
\hline \multirow{3}{*}{ Ano/Tratamento/Dose } & \multirow{3}{*}{$\begin{array}{c}\begin{array}{c}\text { Pré- } \\
\text { Contagem }^{8}\end{array} \\
\mathrm{~N}\end{array}$} & \multicolumn{6}{|c|}{ Dias após a emergência (DAE) } \\
\hline & & \multicolumn{2}{|c|}{30} & \multicolumn{2}{|c|}{60} & \multicolumn{2}{|c|}{90} \\
\hline & & $\mathrm{N}$ & $\% \mathrm{E}^{9}$ & $\mathrm{~N}$ & $\% \mathrm{E}^{9}$ & $\mathrm{~N}$ & $\% \mathrm{E}^{9}$ \\
\hline
\end{tabular}

1999

Testemunha

Fipronil ${ }^{3} 125^{1}$

Fipronil ${ }^{3} 250^{1}$

Fipronil ${ }^{3} 375^{1}$

Clorpirifós ${ }^{4} 1200^{2}$

Lambdacialotrina ${ }^{5} 25^{2}$

$\begin{array}{lc}26,0 \pm 7,78 & 28,0 \pm 6,40 \\ 26,7 \pm 6,91 & 13,3 \pm 4,82 \\ 26,0 \pm 7,22 & 12,0 \pm 4,05 \\ 27,3 \pm 6,74 & 11,3 \pm 3,14 \\ 27,3 \pm 5,51 & 2,0 \pm 1,75 \\ 26,7 \pm 9,42 & 4,0 \pm 2,86\end{array}$

54
57
62
93
86

$14,7 \pm 1,65$

$6,7 \pm 3,87$

$5,3 \pm 2,61$

$3,3 \pm 1,64$

$0,7 \pm 1,30$

$2,7 \pm 1,66$

diminuiu apenas aos 90

DAE, pelo declínio natural nessa época, variando essa queda de $43 \%$ (ano 2000) a $64 \%$ (ano 1999) em relação à população determinada antes da semeadura.

2000

Testemunha $23,3 \pm 8,69 \quad 18,0 \pm 5,76$

Tiametoxam ${ }^{6} 21^{1}$

$22,0 \pm 2,68 \quad 11,3 \pm 4,71$

$22,7 \pm 6,61 \quad 10,0 \pm 4,41$

$22,7 \pm 4,37 \quad 8,7 \pm 3,14$

Tiametoxam ${ }^{6} 63$

$22,7 \pm 5,22 \quad 4,7 \pm 3,14$

Clorpirifós ${ }^{4} 960^{2}$

$22,0 \pm 3,35$

$10,7 \pm 3,35$

$\begin{array}{ll}- & 15,3 \pm 4,71 \\ 34 & 9,6 \pm 2,94 \\ 43 & 6,6 \pm 3,30 \\ 50 & 4,0 \pm 2,86 \\ 73 & 2,7 \pm 1,64 \\ 37 & 7,3 \pm 4,71\end{array}$

${ }^{1} \mathrm{~g}$ i.a./100 kg de sementes.

2 g i.a./hectare.

${ }^{3}$ Standak 250 FS (250 g i.a./litro); ${ }^{4}$ Clorpirifós Milênia 480 CE (480 g i.a./litro); ${ }^{5}$ Karate 50 CE (50 g i.a./litro); ${ }^{6}$ Cruiser 700 WS (700 g i.a./quilo); ${ }^{7}$ Karate Zeon 50 CS (50 g i.a./litro).

${ }^{8}$ Antes da semeadura.

${ }^{9}$ Eficiência relativa calculada pela fórmula de HENDERSON \& TILTON (1955).

sobrepostos na pré-contagem (Tabela 2) demonstram que não houve diferença significativa quanto ao número de larvas antes da semeadura do trigo, indicando densidades populacionais da praga equivalentes entre os tratamentos nas duas áreas experimentais.

As respostas entre doses de inseticidas e número de larvas foram observadas em todas as avaliações efetuadas após a emergência das plantas (DAE), obtendo-se correlações negativas e significativas (Tabela 1). Com o aumento das doses dos inseticidas, decresceu o número de larvas até 90 DAE, sendo que as percentagens de eficiência variaram de 54 a $58 \%$ (fipronil $125 \mathrm{~g}$ i.a./ha), 57 a $65 \%$ (fipronil $250 \mathrm{~g}$ i.a./ha), 62 a $80 \%$ (fipronil $375 \mathrm{~g}$ i.a./ha), 34 a $47 \%$ (tiametoxam $21 \mathrm{~g}$ i.a./ha), 43 a $59 \%$ (tiametoxam $42 \mathrm{~g}$ i.a./ha) e 50 a $73 \%$ (tiametoxam 63g i.a./ha) (Tabela 2). No entanto, os melhores percentuais de controle foram obtidos com os inseticidas aplicados na superfície do solo, em ordem decrescente: 93 a 96\% (clorpirifós 1200g i.a./ha), 82 a $86 \%$ (lambdacialotrina 25 g i.a./ha formulação CE) e 73 a $82 \%$ (clorpirifós $960 \mathrm{~g}$ i.a./ha). Nessa modalidade de aplicação, lambdacialotrina $20 \mathrm{~g}$ i.a./ha (formulação CS) resultou nos percentuais de eficiência mais baixos (37 a 49\%). Na testemunha, o número de larvas
- $\quad 9,3 \pm 4,19$

$564,0 \pm 2,86$

$643,3 \pm 1,30$

$79 \quad 2,0 \pm 1,75$

$96 \quad 0,7 \pm 1,30$

$82 \quad 1,3 \pm 1,65$

$\begin{array}{lll}- & 13,3 \pm 3,30 & - \\ 34 & 6,7 \pm 4,37 & 47 \\ 56 & 5,3 \pm 4,81 & 59 \\ 73 & 4,0 \pm 2,02 & 69 \\ 82 & 2,7 \pm 1,65 & 79 \\ 49 & 6,7 \pm 4,37 & 47\end{array}$

produtividade da cultura (Figuras $1 \mathrm{~A} \mathrm{e} 1 \mathrm{~B}$ ).

As correlações entre doses dos inseticidas e massa seca da parte aérea das plantas aos 90 DAE foram positivas e significativas (Tabela 1), inferindo-se, assim, que os inseticidas proporcionaram proteção às plantas; de fato, a quantidade de biomassa diminuiu à medida que a ação do inseticidas foi mais baixa. Isso ficou evidente desde o início do desenvolvimento vegetativo, quando se observou redução na população de plantas nos tratamentos de menor eficiência, que afetou a

Destaca-se que, nas avaliações efetuadas após a emergência do trigo, a maioria dos inseticidas apresentou eficiência inferior a $80 \%$, especialmente fipronil (com exceção da dose de $375 \mathrm{~g}$ i.a./100kg de sementes aos 90 DAE) e tiametoxam aplicados via tratamento de sementes, além de lambdacialotriana 20 (formulação CS) usado em pulverização do solo (Tabela 2). No entanto, as correlações feitas entre inseticidas e número de larvas, quantidade de massa seca da parte aérea das plantas e produtividade de grãos demonstraram alta relação (Tabela 1). Esses resultados estão de acordo com aqueles obtidos por SILVA (2000), evidenciando a validade desse tipo de análise, que fornece a eficiência dos inseticidas através da proteção das plantas contra o dano da praga. Também os resultados indicam que a avaliação de eficácia de inseticidas, através do índice de mortalidade superior a $80 \%$, não pode ser aplicado isoladamente para insetos rizófagos.

A regressão quadrática expressou o melhor ajuste dos dados para doses de fipronil [ $\mathrm{Y}=$ $\left.112,3+0,938 \mathrm{x}-0,00176 \mathrm{x}^{2}\right]$ e tiametoxam $[\mathrm{Y}=$ $186,8+1,369 x-0,00397 x^{2}$ ] (Figuras 1 A e 1 B). Os coeficientes de determinação foram significativos, atingindo 0,82 para fipronil, e 0,99 para tiametoxam. Esses valores evidenciaram alta relação entre a 
produtividade de trigo e as doses de fipronil e tiametoxam. Com base nessas equações, foi possível estabelecer a máxima eficiência técnica (MET), que foi de 266 e $172 \mathrm{~g}$ i.a./100kg de sementes de trigo para os inseticidas fipronil e tiametoxam, respectivamente.

A ação das larvas causou reduções na
produtividade das testemunhas quando comparadas aos tratamentos com inseticidas, variando entre 51 e $57 \%$ no ano 1999 e 12 e $35 \%$ no ano 2000 (Figuras 1 A e 1 B). Esses resultados corroboram os de SILVA et al. (1995) e SILVA (2000), que determinaram perdas de produtividade de trigo entre 20 e $75 \%$ devido ao ataque de larvas de D. abderus. A maior perda na produtividade de trigo registrada em 1999, em comparação a de 2000, pode ser creditada à atividade das larvas associada aos fatores ambientais, como a estiagem, registrada durante os meses de agosto a outubro de 1999. MOREY \& ALZUGARAY (1982) citam que o dano do inseto é mais severo em anos secos, resultando em plantas mais estressadas e, portanto, com menor tolerância ao ataque das larvas, em relação aos anos normais.

A menor produtividade de grãos de trigo ocorreu nas testemunhas (Figuras 1 A e 1 B), nas quais o número de larvas foi maior (Tabela 2). As parcelas tratadas com fipronil e tiametoxam apresentaram maior produtividade quando comparadas às testemunhas, sendo que as doses de fipronil proporcionaram equivalência estatística a lambdacialotrina 25 (formulação CE) e clorpirifós 1200, enquanto que as doses de tiametoxam e lambdacialotrina 20 (formulação CS) resultaram em produtividades significativamente menores que a de clorpirifós 960. Os resultados de



Figura 1 - Produtividade de grãos de trigo em diferentes tratamentos com e sem inseticidas usados para o controle de larvas de Diloboderus abderus. Valores identificados com a mesma letra, para cada ano [1999 (A), CV =11,3\%; 2000 (B), CV = 5,6\%] não são significativamente diferentes pelo teste de Tukey ao nível de $5 \%$ de probabilidade de erro. Cruz Alta, RS, 2001 
de tiametoxam e doses mais baixas de fipronil devem ser testadas, para se determinarem as doses técnica e economicamente mais adequadas. Em caso positivo, essas substâncias podem ser recomendadas, já que em outras pesquisas feitas por ALZUGARAY et al. (1991), GASSEN (1993), SILVA et al. (1995) e SILVA (2000) o tratamento de sementes com inseticidas (carbaril, carbofuram, carbossulfam, clorpirifós, diazinom, furatiocarbe, imidaclopride e tiodicarbe) foi uma alternativa eficiente para proteger plantas de trigo do ataque de larvas de $\boldsymbol{D}$. abderus. Lambdacialotrina (formulação CS), aplicado em pulverização na superfície do solo em 2000, resultou em perda significativa de eficiência no controle das populações da praga quando comparado com os melhores tratamentos. Isso evidencia a necessidade de novos testes, para determinar a dose mais adequada dessa formulação, visando o controle de larvas de D. abderus. Os inseticidas clorpirifós, nas dose de 960 e $1200 \mathrm{~g}$ i.a./ha, e lambdacialotrina (formulação CE), na dose de $25 \mathrm{~g}$ i.a./ha, aplicados em pulverização na superfície do solo, foram eficientes na redução das perdas de produtividade das plantas de trigo causadas pelas larvas de D. abderus, em plantio direto.

\section{CONCLUSÕES}

Os inseticidas clorpirifós a 960 e $1200 \mathrm{~g}$ i.a./ha e lambdacialotrina (formulação CE) a $25 \mathrm{~g}$ i.a./ha, aplicados em pulverização na superfície do solo, protegem eficientemente plantas de trigo em áreas infestadas por larvas de $\boldsymbol{D}$. abderus, no sistema plantio direto.

São necessárias novas pesquisas com os inseticidas fipronil, tiametoxam e lambdacialotrina (formulação SC) para determinar as doses mais adequadas técnica e economicamente no controle de larvas de $\boldsymbol{D}$. abderus.

\section{AGRADECIMENTOS}

Agradecemos ao pesquisador Giovani Theisen pelas sugestões em versões preliminares do manuscrito.

\section{REFERÊNCIAS BIBLIOGRÁFICAS}

ALVARADO, L. Dãnos de insectos de suelo en semillas de plantas cultivadas. Pergamino : INTA/EERA, 1983. 7p. (Informe Tecnico, 180).

ALVARADO, L.; IZQUIERDO, J.A.; ENECOIZ, M.A. Eficacia del tratamiento de semillas de maíz con carbofuran sobre larvas de Diloboderus abderus (Sturm). In: ACTAS CONGRESSO NACIONAL DEL MAÍZ, 2, 1981, Pergamino. Actas... Pergamino : INTA/EERA, 1981 p.168-177.

ALZUGARAY, R.; LONG, C.; CASAS, J. Control de isocas en trigo. Montevideo : INIA, 1991. 4 p. (Hoja de Divulgación, 20).

COCHRAN, W.G.; COX, G.M. Diseños experimentales. México : Trillas, 1971. 661p.

GASSEN, D.N. Diloboderus abderus (Coleoptera: Melolonthidae) in no-tillage farming in Southern Brazil. In: MORÓN, M.A. (Comp.). Diversidad y manejo de plagas subterraneas. México : Sociedad Mexicana de Entomología e Instituto de Ecología, 1993. p.129-141.

HENDERSON, C.F.; TILTON, E.W. Tests with acaricides against the brown wheat mite. Journal of Economic Entomology, College Park, v.48, n.1, p.157-161, 1955.

MOREY, C.S.; ALZUGARAY, R. Biologia y comportamiento de Diloboderus abderus (Sturm) (Coleoptera:Scarabaeidae). Montevideo : Ministerio de Agricultura y Pesca/Dirección de Sanidad Vegetal, 1982. 44p. (Boletín Tecnico, 5).

SILVA, A.G.d'A.; GONÇALVES, C.R.; GALVÃO, D.M., et al. Quarto catálago dos insetos que vivem nas plantas cultivadas do Brasil; seus parasitos e predadores. Rio de Janeiro : Ministério da Agricultura, 1968. V.1, pt. 2, 622p.

SILVA, M.T.B. Controle de larvas de Diloboderus abderus Sturm (Coleoptera: Melolonthidae) via tratamento de sementes de trigo com inseticidas no plantio direto. Anais da Sociedade Entomológica do Brasil, Londrina, v.29, n.1, p.123-129, 2000.

SILVA, M.T.B. da; LINK, D.; COSTA, E.C., et al. Efeito da época de semeadura de milho sobre os danos causados pelas larvas de Diloboderus abderus (Sturm) (Coleoptera: Melolonthidae) em plantio direto. Anais da Sociedade Entomológica do Brasil, Londrina, v.25, n.1, p.89-94, 1996.

SILVA, M.T.B. da; KLEIN, V.A.; REINERT, D.J. Controle de larvas de Diloboderus abderus Sturm (Coleoptera: Melolonthidae) por sistemas de manejo de solos em trigo. Anais da Sociedade Entomológica do Brasil, Londrina, v.24, n.2, p.227-232, 1995.

SILVA, M.T.B. da; KLEIN, V.A.; LINK, D., et al. Influência de sistemas de manejo de solos na oviposição de Diloboderus abderus Sturm (Coleoptera: Melolonthidae). Anais da Sociedade Entomológica do Brasil, Londrina, v.23, n.3, p.543-548, 1994. 